Bull. Austral. Math. Soc.

VoL. 75 (2007) [151-151]

\title{
CORRIGENDUM: THE HELGASON FOURIER TRANSFORM FOR SEMISIMPLE LIE GROUPS I: THE CASE OF $S L_{2}(R)$
}

\section{Rudra P. Sarkar and Alladi Sitaram}

The following changes should be made to the paper which appeared in (Bull. Astral. Math. Soc. Vol. 73 (2006) [413-432]).

Let $f^{\#}(x)=f\left(x^{-1}\right)$.

1 Replace $\pi(f)$ by $\pi\left(f^{\#}\right)$ in Line 7 of the introduction; that is, in the line starting "Even when $\pi$ is of class one..."

2 Replace $\pi(f)$ by $\pi\left(f^{\#}\right)$ in Line 8 (in both the places) of the introduction.

3 Replace $\pi_{\lambda}(f)$ by $\pi_{\lambda}\left(f^{\#}\right)$ in Line 13 of the introduction.

4 Replace $\pi_{-l}(f)$ by $\pi_{-l}\left(f^{\#}\right)$ in the last line of page 418 .

5 Replace $\pi_{l}(f)$ by $\pi_{l}\left(f^{\#}\right)$ in Line 2 of page 419 .

These changes have to be made in order that the relationship between the group theoretic Fourier transform and the Helgason Fourier transform is completely accurate.

\author{
Stat-Math Unit \\ Indian Statistical Institute \\ 203 B. T. Road \\ Calcutta 700108 \\ India \\ e-mail: rudra@isical.ac.in
}

\author{
Stat-Math Unit \\ Indian Statistical Institute, \\ 8 th Mile, Mysore Rd. \\ Bangalore 560059 \\ India \\ e-mail: sitaram@isibang.ac.in
}

Received 30th October, 2006

Copyright Clearance Centre, Inc. Serial-fee code: 0004-9727/07 $\$ A 2.00+0.00$. 